Article

\title{
Potential of Rainwater Utilization in Households Based on the Distributions of Catchment Area and End-Use Water Demand
}

\author{
Kaori Takagi ${ }^{1, *}$, Masahiro Otaki ${ }^{2}$ and Yurina Otaki ${ }^{3}$ \\ 1 Department of Human Centered Engineering, Ochanomizu University, Tokyo 112-8610, Japan \\ 2 Faculty of Core Research, Natural Science Division, Ochanomizu University, Tokyo 112-8610, Japan; \\ otaki.masahiro@ocha.ac.jp \\ 3 Graduate School of Social Sciences, Hitotsubashi University, Tokyo 186-8601, Japan; \\ yurina.otaki@r.hit-u.ac.jp \\ * Correspondence: takagi.kaori@outlook.jp; Tel.: +81-3-5978-5747
}

Received: 19 October 2018; Accepted: 17 November 2018; Published: 22 November 2018

\begin{abstract}
In the area where household water use exceeds the capacity of the public water supply, rainwater is considered as one of the alternative water resources. Many researchers studied rainwater potential to cover the specific value of water demand in households having the average catchment area, so that the estimated potential expresses that of the average population. In this research, the possibility of rainwater use for toilets was investigated more realistically using the probability distributions of water demand and catchment area, and precipitation in case of Hanoi, Vietnam. Monte Carlo simulations were conducted throughout this simulation and the distribution of the possibility of rainwater use was estimated. The effect of household size and seasonal variations on the potential of rainwater utilization was also assessed. These results showed that our new approach exhibited that approximately $60 \%$ of the households failed to achieve the potential that was estimated using the conventional approach. Therefore, our new approach should be useful to understand the manner in which the potential of rainwater utilization differs in a given area, and it could be applied to other areas for consideration on the rainwater use potential and the suitable tank size when the distributions of variables and precipitation are clear.
\end{abstract}

Keywords: rainwater utilization; end use water demand; Monte Carlo simulation

\section{Introduction}

In several areas of the world, the household water demand is observed to exceed the capacity of public water supply. The factors that contribute to water shortage include climate change, rapid population increase, economic growth, and insufficient water supply [1,2]. Especially, the accelerating population growth in developing countries is expected to increase the difference between demand and supply in future years. Furthermore, the Environmental Outlook Baseline scenario projects that, by 2050 , the global water demand will be $55 \%$ larger than that in 2000 because of the increasing demands of manufacturing $(+400 \%)$, electricity $(+140 \%)$, and domestic usage $(+130 \%)$ [3]. Domestic usage should be prioritized in terms of water allocation because it is essential to maintain suitable public health and living standards. Traditionally, household water usage has been managed by supply augmentation [4]; however, the current water supplies are threatened by climatic changes such as floods and droughts [5]. A potential alternative to supply augmentation is water demand management [5-7]. The various methods of water demand measurement [8-10] can be classified into the following two groups: 1 . Measures for reducing the water demand, and 2. measures for reducing the demand of public water supply. The water demand can be reduced by technological improvements, 
such as by installing water-efficient devices, or by behavioral approaches, such as by adjusting the water pricing and by imposing water restrictions $[9,11]$. The demand of public water supply can be reduced by substituting it with alternative water resources [12,13].

The current study focuses on alternative water resources. Reclaimed wastewater and desalinated water have been used for several decades [14]. However, reclaimed water requires complicated treatment before household usage, and desalinated water is facing several problems based on technology, energy, and cost [15]. These difficulties can be overcome using greywater and rainwater. Rainwater is an especially attractive resource, and its household utilization is encouraged because it is easily harvested and stored in household reservoirs; further, the quality of rainwater is considered to be suitable for almost every purpose except for potable use [16]. Furthermore, rainwater harvesting improves the stormwater drainage systems [17]. In fact, introducing rainwater-harvesting systems for non-potable purposes is a global effort. Australia is a representative country that has implemented rainwater-harvesting systems for household usage. For instance, an estimated $40 \mathrm{GL}$ of water from household rainwater tanks was utilized in New South Wales [18]. Further, rainwater harvesting has deployed not only in arid or semi-arid regions, but also in various developing countries. The United Nations Environment Programme emphasized that efficient rainwater harvesting systems can provide water and affordable food to populations in developing countries [17]. Several Thai households use rainwater for drinking [19], whereas Malaysian households collect rainwater for non-potable uses such as general washing and gardening [20].

In several studies that are related to household rainwater utilization, the potential benefits are observed to be based on the available rainwater volume and end-use water demand. The available rainwater volume in households can be estimated based on the local precipitation, catchment area, and tank size, which are quantifiable variables. One study related to water demand estimated the potential of rainwater utilization based on the specific value of monthly demands [21]. Another study estimated the potential for saving potable water in a simulation study. The input data included the surveyed water demand data of two houses, which may not be sufficient to represent the different water demands of individual households [22]. These studies assumed the precipitation that was recorded in the target area [21-23], and where relevant, the average catchment area [21] along with the specific values of the tank size [22,23].

Thus, the potential of rainwater utilization in households have been discussed based on the representative values of catchment area and water demand such as average value in previous studies. However, they are observed to differ among various houses. Dimensionless analysis has been conducted to consider this uncertainty using the demand fraction, and the storage fraction. The demand fraction is given by $D / A R$, where $D$ is the demand $\left(\mathrm{m}^{3}\right), A$ is the roof area $\left(\mathrm{m}^{2}\right)$, and $R$ is the precipitation $(\mathrm{m})$, and the storage fraction is given by $S / A R$, where $S$ is the tank capacity $\left(\mathrm{m}^{3}\right)$ [24-26]. In another study, the modified storage fraction was used instead of the storage fraction. This is given by $S /\left(D \cdot n_{D} / n_{R}\right)$, where $n_{\mathrm{D}}$ and $n_{\mathrm{R}}$ are the number of dry and rainy days, respectively [27]. By using these values, we can estimate the potential of rainwater utilization for different combinations of demand, roof area, precipitation, and storage fraction. However, the demand and the roof area should have a specific distribution, respectively, so that the potential of rainwater utilization have a distribution too. Hence, the distributions of the uncertain variables should be considered to understand the realistic potential of rainwater utilization. To analyze the probabilistic potential, we use Monte Carlo simulations, which determine the probability distribution of different outcomes from those of the input variables (namely, the catchment area and end-use water demand), and the precipitation data recorded in Hanoi, Vietnam. The simulation results were evaluated in comparison with the potential estimated from the specific value of water demand and the average roof area, as previous researches evaluated [21]. We also varied the household size and investigated the resulting changes in the annual potential of rainwater utilization. The effect of seasonal variations in monthly precipitation on the potential of rainwater utilization was further assessed. The variable distributions were determined from the measured data that were obtained from prior research [28] or the data derived from published maps. 


\section{Methods}

\subsection{Simulation Model}

Figure 1 schematizes the rainwater utilization system that is considered in this research. The rainwater is harvested from the roofs of houses and is stored in rainwater tanks. When the stored rainwater exceeds the tank volume, it is discarded by overflow [29]. Figure 2 is a detailed flowchart of the simulation. The rainwater is presumably used in detached houses, and the runoff coefficient, $C f$, is assumed to be 0.9 [22]. The rainwater is assumed to satisfy the usage demand for toilets alone.

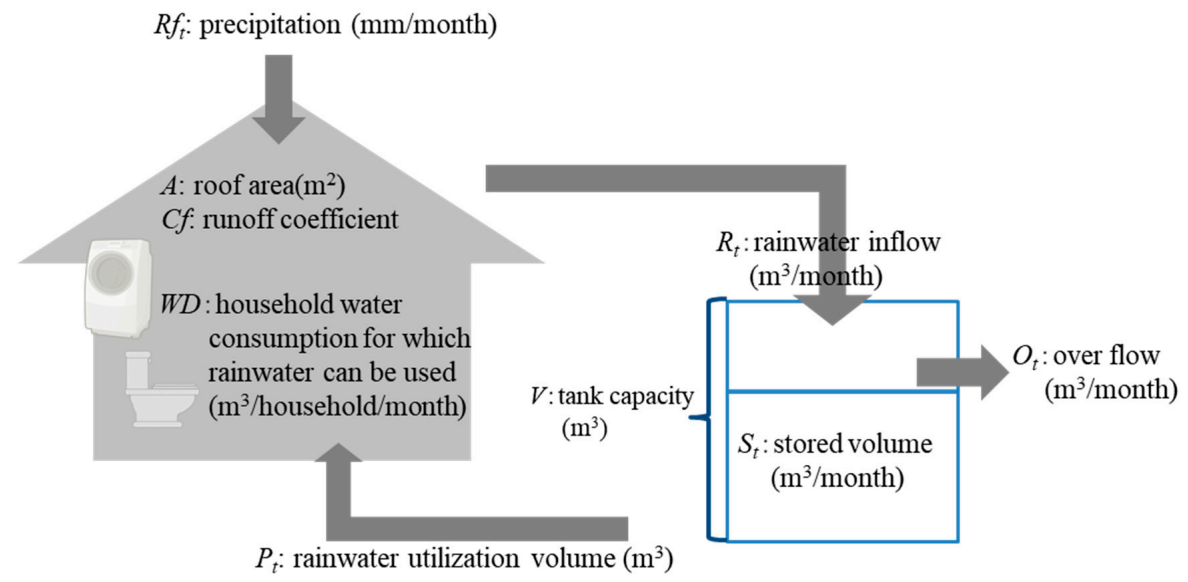

Figure 1. The schematic of rainwater utilization model.

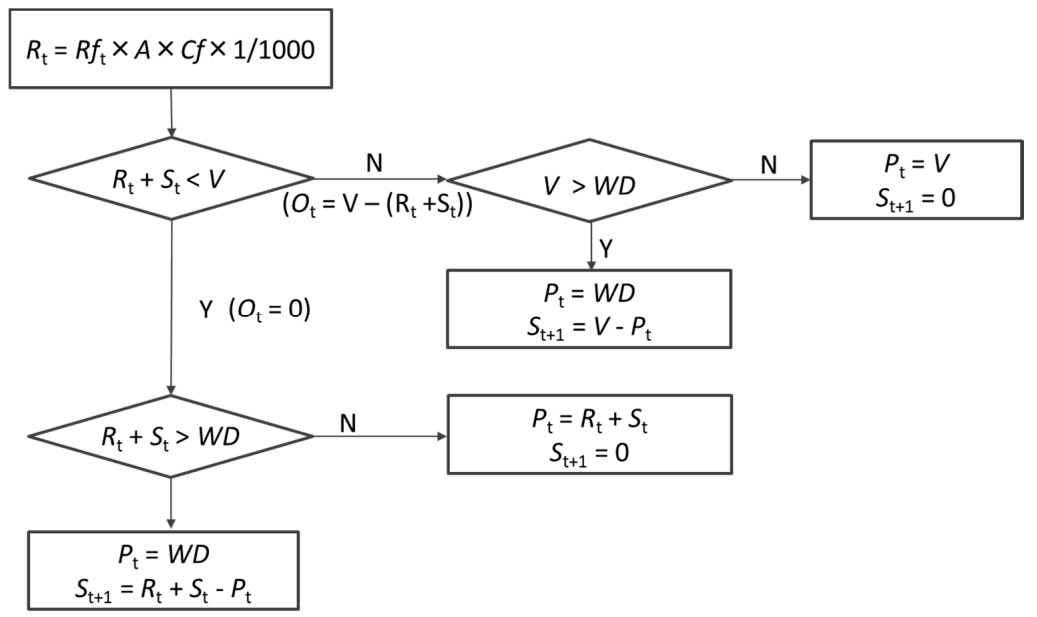

Figure 2. The Model flow chart.

For evaluation purposes, the covering ratio of rainwater utilization was estimated using the following equation.

$$
C(\%)=\frac{\sum_{t=0}^{d} P_{t}\left(\mathrm{~m}^{3}\right)}{W D\left(\mathrm{~m}^{3} / \text { household } / \text { month }\right) \times d(\text { months })} \times 100
$$

$C$ : Covering ratio of demand of public water supply by rainwater utilization (\%), t: time, $P_{t}$ : Possible rainwater utilization volume $\left(\mathrm{m}^{3}\right), W D$ : household water demand for toilets $\left(\mathrm{m}^{3} /\right.$ household $\left./ \mathrm{month}\right)$, $d$ : duration (months).

This model was run with two following approaches: 1. Probabilistic approach, 2. Conventional approach. 


\subsubsection{Probabilistic Approach}

Ten-thousand runs following Monte Carlo simulation of the model, shown in Figure 2, were executed in Oracle Crystal Ball 11.1.2.3.500 (Figure 3). This simulation generated the covering ratio, $C_{P}$, using Equation (1) for a particular combination of randomly selected parameters, roof area, and toilet water demand, which follow their own probability distributions. The determination ways of these probability distributions are shown in Section 2.2. In each simulation, the possible rainwater utilization volume, $P_{t}$, was estimated for every month of the simulation duration (see Figure 2). Further, the $P_{t}$ distribution was calculated for each month, and its probability distribution throughout the simulation duration was also estimated by Monte Carlo simulation. Finally, the probability distribution of the covering ratio, $C_{P}$, of the water demand that was satisfied by the utilization of rainwater was calculated by Equation (1), as mentioned above.

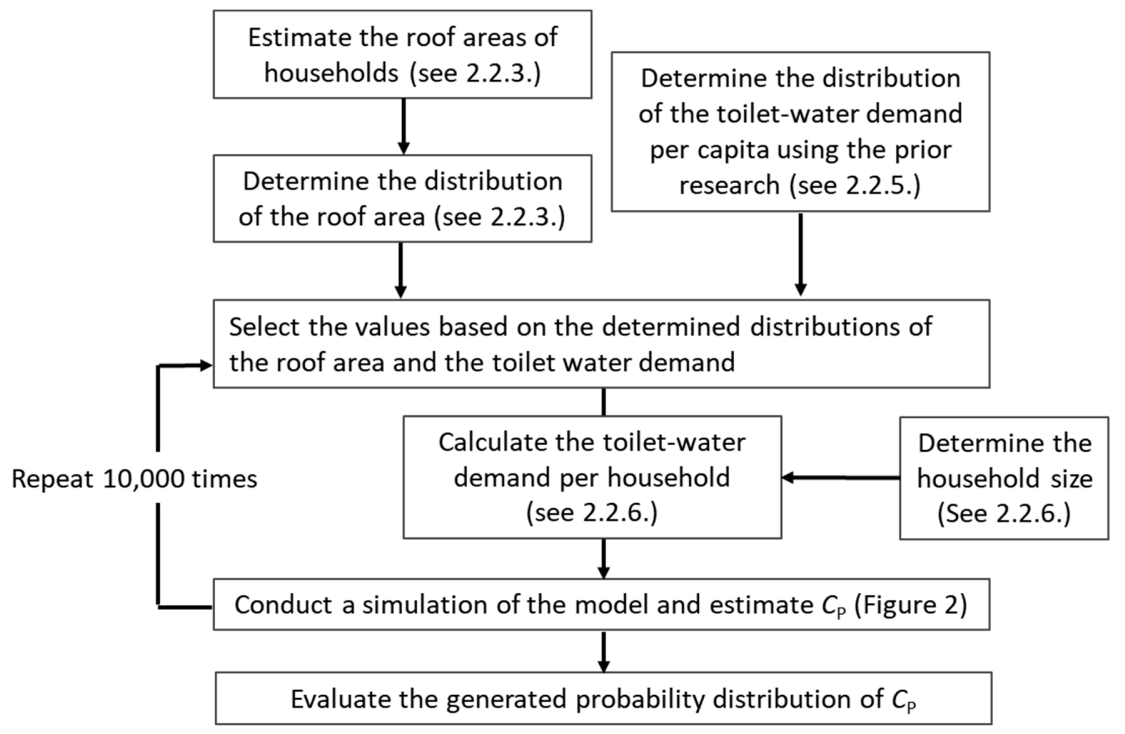

Figure 3. Flow of probabilistic approach.

\subsubsection{Conventional Approach}

A run of the model, shown in Figure 2, was executed using fixed values of the roof area and water demand (Figure 4). The roof area and the water demand were determined as the average value, and the specific demand, respectively, following a previous study [21]. These determined values are shown in Section 2.2. This approach determines the possible rainwater utilization volume, $P_{t}$, for every month of the simulation duration. The covering ratio, $C_{C}$, of the demand of public water supply were calculated by Equation (1) too.

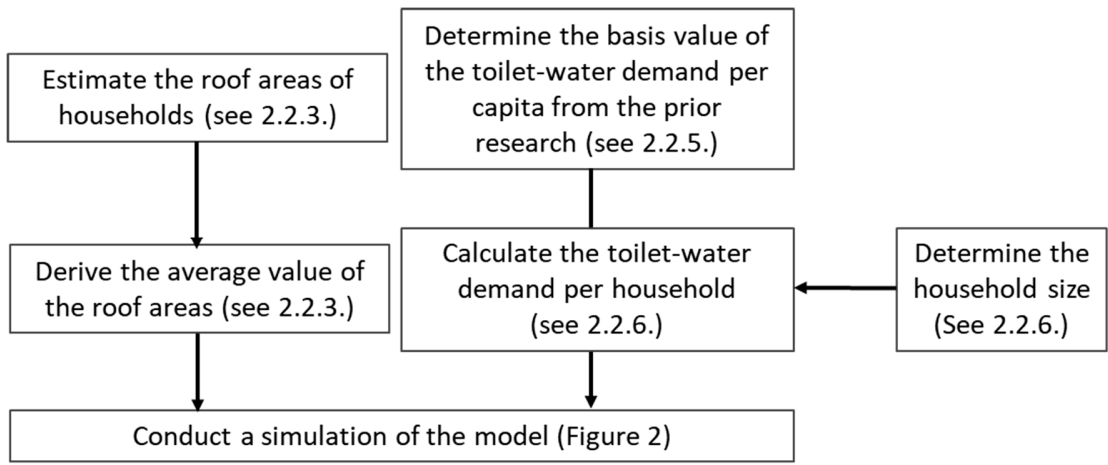

Figure 4. Flow of conventional approach. 


\subsection{Data Utilized for Simulations}

\subsubsection{Targeted Area}

In this study, we have investigated the potential of rainwater utilization in Hanoi, Vietnam, where the toilet-water demand was investigated in the previous study. Hanoi is located in the Northern part of Vietnam which has a population of 7,420,100 inhabitants [30]. In this study, we refer the data of water demand from a study, which was investigated in three areas of Hanoi, including Thanh Tri, Gia Thuong Bac Bien, and Vinh Quynh (Figure 5).

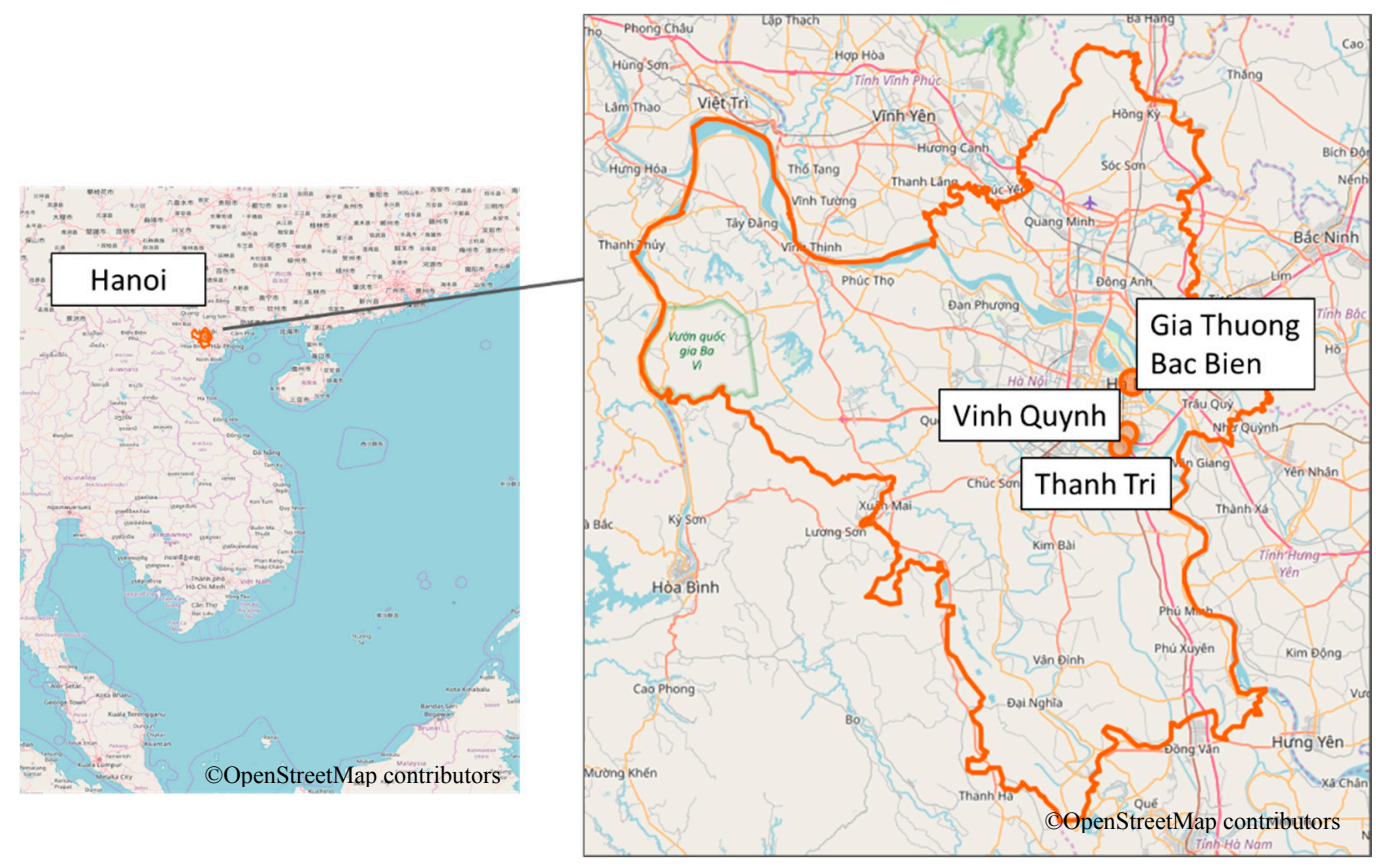

Figure 5. The location of the targeted area in Vietnam.

\subsubsection{Precipitation}

Some studies recommended that simulations using precipitation of 10-year time series length [31,32]. Therefore, the input data of the simulations were the monthly precipitation data of Hanoi that were obtained from General Statistics of Vietnam from January 2008 to December 2017 [33]. The model was run over these five years, and the results were displayed from 2009 onward (the results of the first year, which assumed that rainwater tanks were installed in households in the simulation, were omitted).

\subsubsection{Distribution of the Catchment Areas}

The rainwater catchment area was defined as the projected area of the house roof [34]. The photomap was derived from Google Earth, and the roof area was estimated using Image J software. This study analyzed the projected roof areas of 1653 households in three areas, shown in Figure 5. The roofs of the detached houses (assumed to have areas of less than $200 \mathrm{~m}^{2}$ ) were selected for conducting the study; large areas were assumed to belong to business, and other types of buildings, such as corporate buildings, were excluded. The minimum, maximum, and average areas of the presumed detached houses were 9,199 , and $66.3 \mathrm{~m}^{2}$, respectively. In the probabilistic approach, because the projected roof area did not follow a normal or log-normal distribution, it was represented as a histogram (see Figure 6) and was directly applied in this study. The bin width was calculated as $20 \mathrm{~m}^{2}$, based on Sturges' formula. In the conventional approach, the average value was applied. 


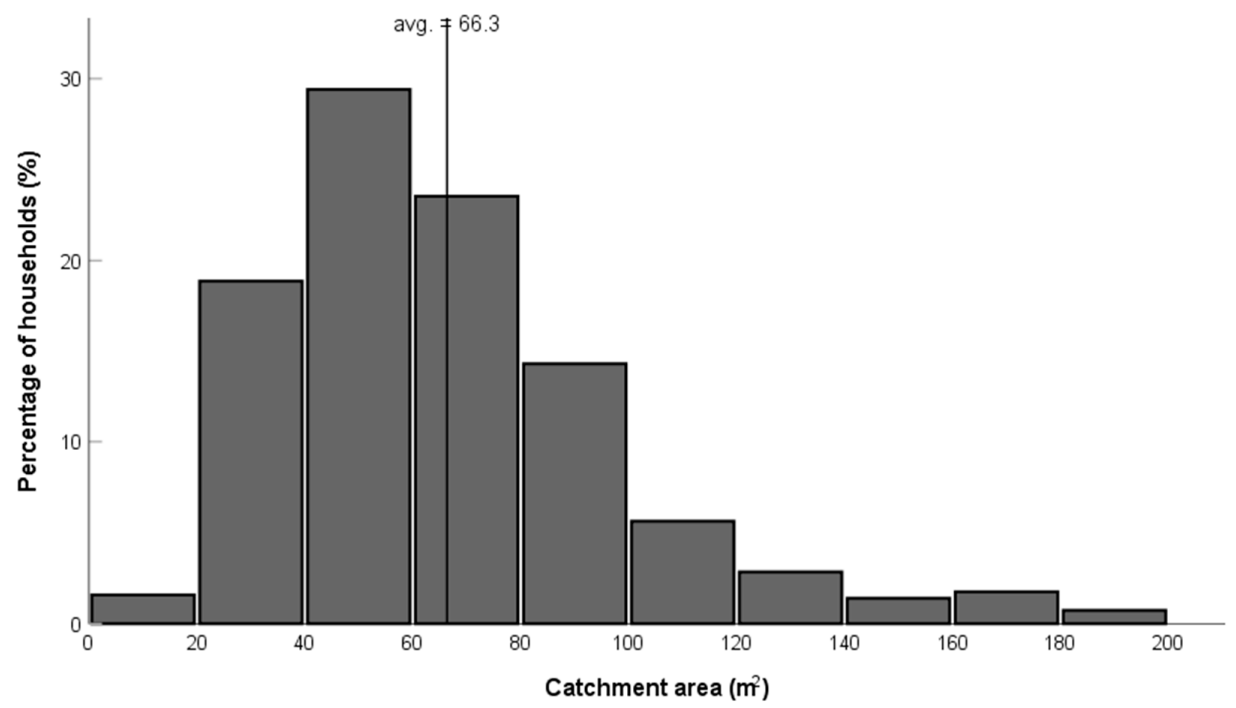

Figure 6. Distribution of catchment area.

\subsubsection{Rainwater Tank Size}

Further, various methods have been discussed for determining the rainwater tank size [22,35]; however, no standard approach exists to perform this calculation.

A study indicated that the tank size was ideal when the saving potential of potable water increased by less than $1.0 \%$ after increasing the rainwater-tank volume by $1000 \mathrm{~L}$ [22]. Ward et al. [35] calculated the tank size from the catchment area, runoff coefficient, system filter efficiency, and average annual precipitation. In the present study, we assessed the representative tank size using the following equation [36]:

$$
V\left(\mathrm{~m}^{3}\right)=A\left(\mathrm{~m}^{2}\right) \times 0.1(\mathrm{~m})
$$

$V$ : tank capacity $\left(\mathrm{m}^{3}\right)$, and $A$ : roof area $\left(\mathrm{m}^{2}\right)$.

Using Equation (2), the average tank size was estimated to be approximately $7-\mathrm{m}^{3}$. However, the required tank size should vary with the precipitation conditions, water demand, household size, and other factors. To understand the minimum and the maximum potential of rainwater utilization, we varied the tank size from $1-\mathrm{m}^{3}$, which is small enough to install in households easily, to $20-\mathrm{m}^{3}$, which is assumed to be large enough to store most of the captured rainfall in general, in $1-\mathrm{m}^{3}$ increments.

\subsubsection{Distribution of Toilet-Water Demand Per Capita}

The probability distribution of the toilet-water demand per capita was derived from a survey conducted for two months from March 2011 in Hanoi, Vietnam [28]. This survey targeted 56 households, and we derived the data of 31 households in which toilet-water demand was measured successfully. The averages and variances of the natural logarithmic values of the toilet-water demand did not significantly depend on the household size (Levene's test: $\mathrm{W}=0.863, p=0.520$, Variance analysis: $\mathrm{F}=1.473, p=0.230$ ). Therefore, the end-use water demand in this study could not be distinguished based on the household size. The data of toilet-water demand per capita is renowned to follow a log-normal distribution [28]. The log-normal probability of the toilet-water demand is displayed in Figure 7. The average and standard deviation of the toilet-water demand were calculated from the actual toilet-water demand, as the average of the natural logarithmic values $=2.98 \mathrm{~L} /$ cap. $/$ day (antilogarithmic value $=19.7 \mathrm{~L} /$ cap. $/$ day), and the standard deviation $=0.45 \mathrm{~L} /$ cap. $/$ day (antilogarithmic value $=1.57 \mathrm{~L} /$ cap. $/$ day). In addition, the total water consumption was $124.8 \mathrm{~L} /$ cap./day in 2011 in Hanoi, according to the statistics [37], so that the ratio of the toilet to the total-water demand was expected to be approximately $16 \%$ on average. The determined log-normal 
distribution of the toilet-water demand was referred to as the probabilistic approach, and the average was referred to as the conventional approach, as the specific demand.

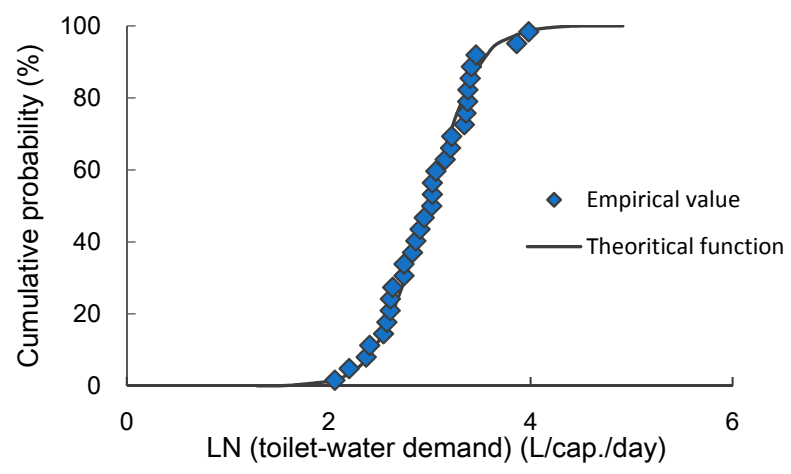

Figure 7. Lognormal probability plots of toilet water demand per capita.

\subsubsection{Household Size}

The potential of rainwater utilization in an average household (3.6 persons/household) [38] was considered. Furthermore, we investigated small (two persons/household) and large (five persons/household) households to determine the effect of household size on the potential of rainwater utilization. The household size was used to estimate the toilet-water demand per household by multiplying it by the toilet water demand per capita.

\section{Results}

\subsection{Estimated Potential of Rainwater Utilization}

Figure 8 depicts the ratios of households with different covering potentials, $C_{P}$, of the demand of public water supply. These results were obtained by the probabilistic approach of toilet-water demand in an average household (3.6 persons/household) with a tank having a representative size $\left(7-\mathrm{m}^{3}\right)$ throughout the simulation. From Figure 8, it was found that all households can satisfy at least half of their toilet water demands using the rainwater captured in their tanks. In addition, the ratio of households, which can cover total toilet water demands, was estimated as approximately $40 \%$ of the households. Conversely, the covering potential, $C_{C}$, was estimated to be $100 \%$ when using the average catchment area and the average toilet-water demand based on the conventional approach. Clearly, the conventional approach overestimated the covering potential, neglecting approximately $60 \%$ of the households with an insufficient coverage. Consequently, the conventional approach will considerably misrepresent the potential of rainwater utilization.

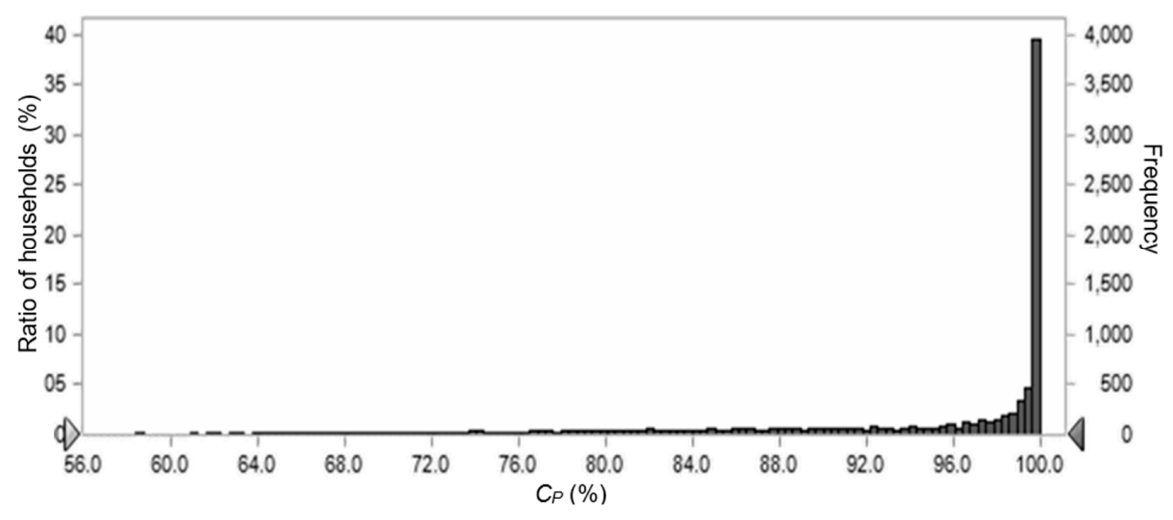

Figure 8. Distribution of the covering ratio of supplied water, $C_{P}$. 
We further integrated the ratios of households whose toilet-water demands were satisfied using rainwater at different portions of the year: more than 182.5 days $\left(C_{P} \geq 50 \%\right)$, more than 328.5 days $\left(C_{P} \geq 90 \%\right)$, and 365 days $\left(C_{P}=100 \%\right)$, using the estimated distribution of the covering potential by the probabilistic approach. Figure 9 depicts the accumulated ratios at each tank volume for an average household size (3.6 persons/house). The ratio of households, for which $C_{P}$ exceeded $50 \%$, were not considerably different among the tank sizes when the tank size is three $\mathrm{m}^{3}$ or more; further, a three $\mathrm{m}^{3}$ tank would satisfy the toilet-water demands of almost all the households. When the required covering ratio exceeds $90 \%$ of that observed in a year, a four $\mathrm{m}^{3}$ tank should be able to satisfy the needs of almost $50 \%$ of the households of the average size. However, to satisfy the toilet-water demands of all households of the average size over the complete year, the tank size must be increased so that it has a capacity of more than $20-\mathrm{m}^{3}$. This result confirms that the required tank size considerably depends on the required covering ratio.

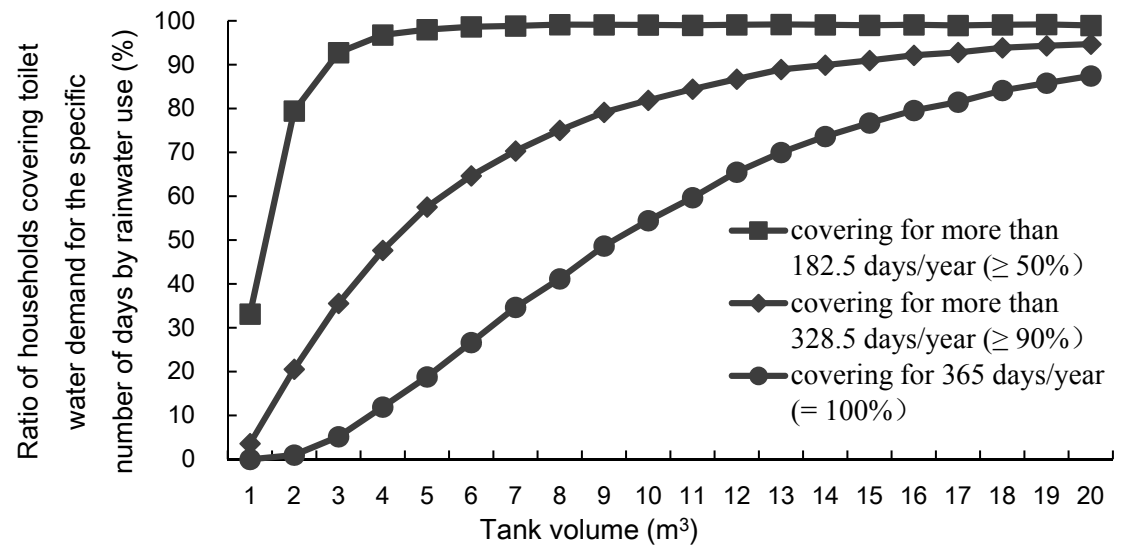

Figure 9. Ratio of households covering water demand by rainwater and tank volume having 3.6 persons.

\subsection{Potential of Rainwater Utilization for Toilet-Water in Households of Different Sizes}

We estimated the potential of rainwater utilization in a household of average size (3.6 persons/household). In this part, we investigate the effect of household size on the potential of rainwater utilization. From panels $(\mathrm{a}-\mathrm{c})$ of Figure 10, we can estimate the required tank size that guarantees $90 \%$ coverage for more than 182.5 days $\left(C_{P} \geq 50 \%\right)$, more than 328.5 days $\left(C_{P} \geq 90 \%\right)$, and 365 days $\left(C_{P} \geq 100 \%\right)$ in the large, average, and small-sized households, respectively. From Figure 10a, we can observe that the demands of more than $90 \%$ of the large, average, small-sized households were satisfied by a tank of five, three, and two $\mathrm{m}^{3}$, respectively, for half of the year. In Figure $10 \mathrm{~b}$, the tank size that guaranteed $90 \%$ coverage of all households for $90 \%$ of the year strongly depended on the household size. More specifically, the demands of the small and average-sized households were satisfied by five and $15-\mathrm{m}^{3}$ tanks, respectively; however, those of the large households were not satisfied by a $20-\mathrm{m}^{3}$ tank. Furthermore, a tank size of $20-\mathrm{m}^{3}$ was considered to be impractical because of the high cost and the required installation area. From Figure 10c, we can estimate that $79 \%$ of the two-person households gain adequate coverage from a seven $\mathrm{m}^{3}$ tank throughout the whole year. However, in large households (with five persons), a 20- $\mathrm{m}^{3}$ tank can satisfy the requirements of only $68 \%$ of the households throughout the whole year. Consequently, full-year coverage of the toilet-water demand by rainwater alone is considered to be impractical in households with more than two persons. 


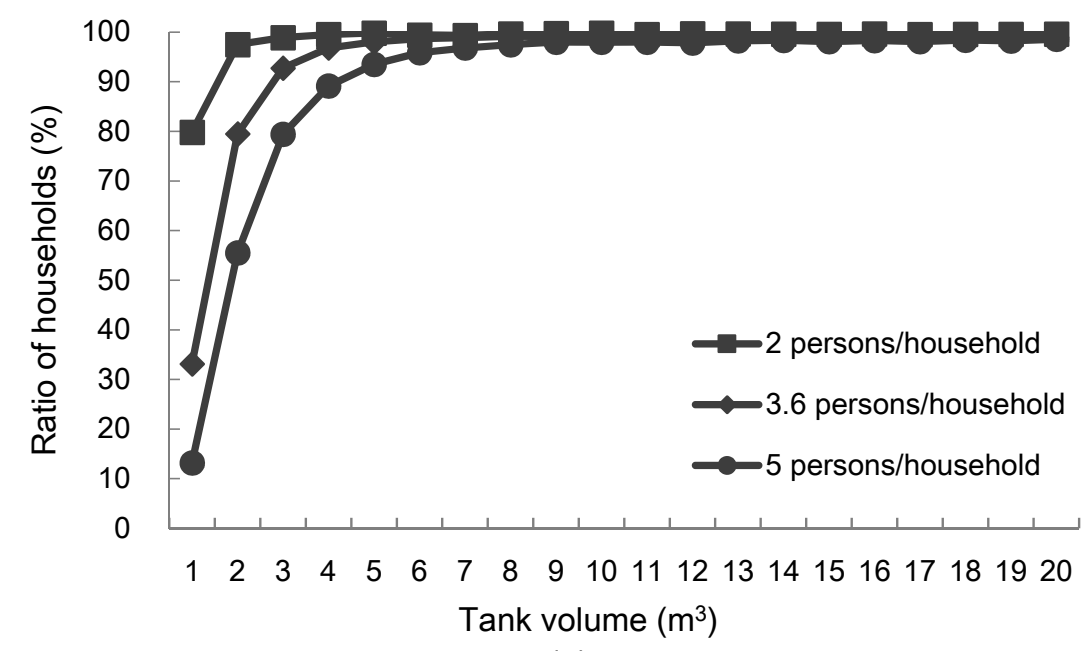

(a)

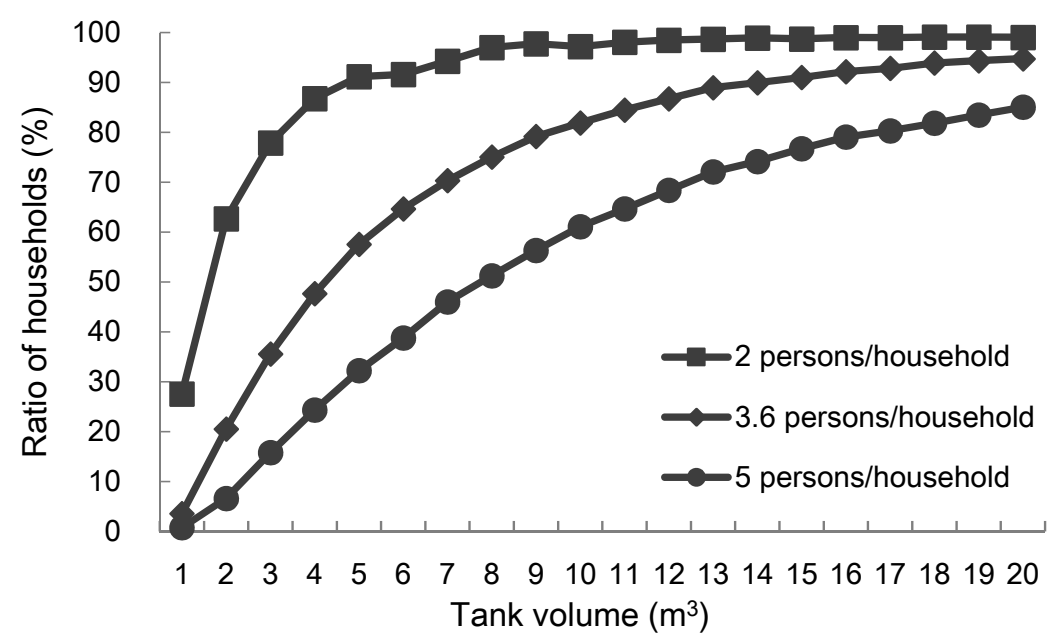

(b)

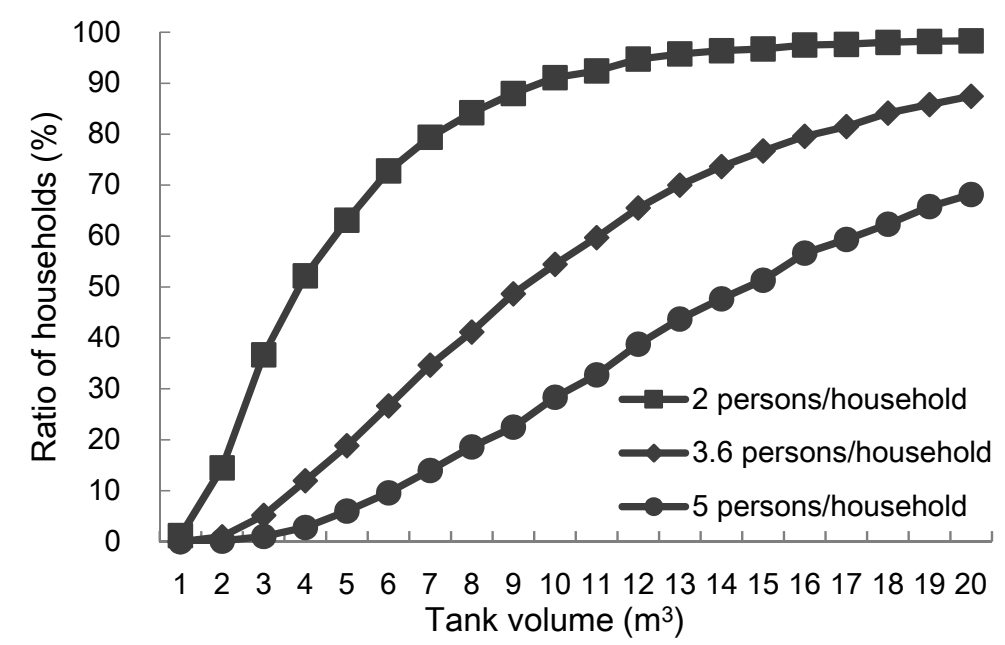

(c)

Figure 10. Comparison of ratio of households which can cover toilet water demand among household sizes: (a) $C_{P} \geq 50 \%$, (b) $C_{P} \geq 90 \%$, and (c) $C_{P}=100 \%$. 


\subsection{Seasonal Change in the Potential of Rainwater Utilization for Toilet Requirements}

To understand the seasonal change in the potential of rainwater utilization, we estimated the covering ratios, $C_{P}$ and $C_{c}$, in each month. Figure 11 depicts the relation between the precipitation and the estimated averages of $C_{P}$ and $C_{c}$ in a tank of representative size (seven $\mathrm{m}^{3}$ ). The conventional approach estimated that rainwater satisfied all the toilet-water demands throughout the simulation. However, in the probabilistic approach, the average covering ratio fluctuated between approximately $60 \%$ and $100 \%$. Further, the potential of rainwater utilization responded to the precipitation in a probabilistic approach but not in the conventional approach. The covering ratio in the probabilistic approach was also influenced by the previous precipitation pattern. This behavior reflects the storage of rainwater in months of high rainfall even though the precipitation may be less than the precipitation in the previous month. Furthermore, the present study used the monthly precipitation data; however, applying the daily precipitation data would result in the precise estimation of the changes in water availability.

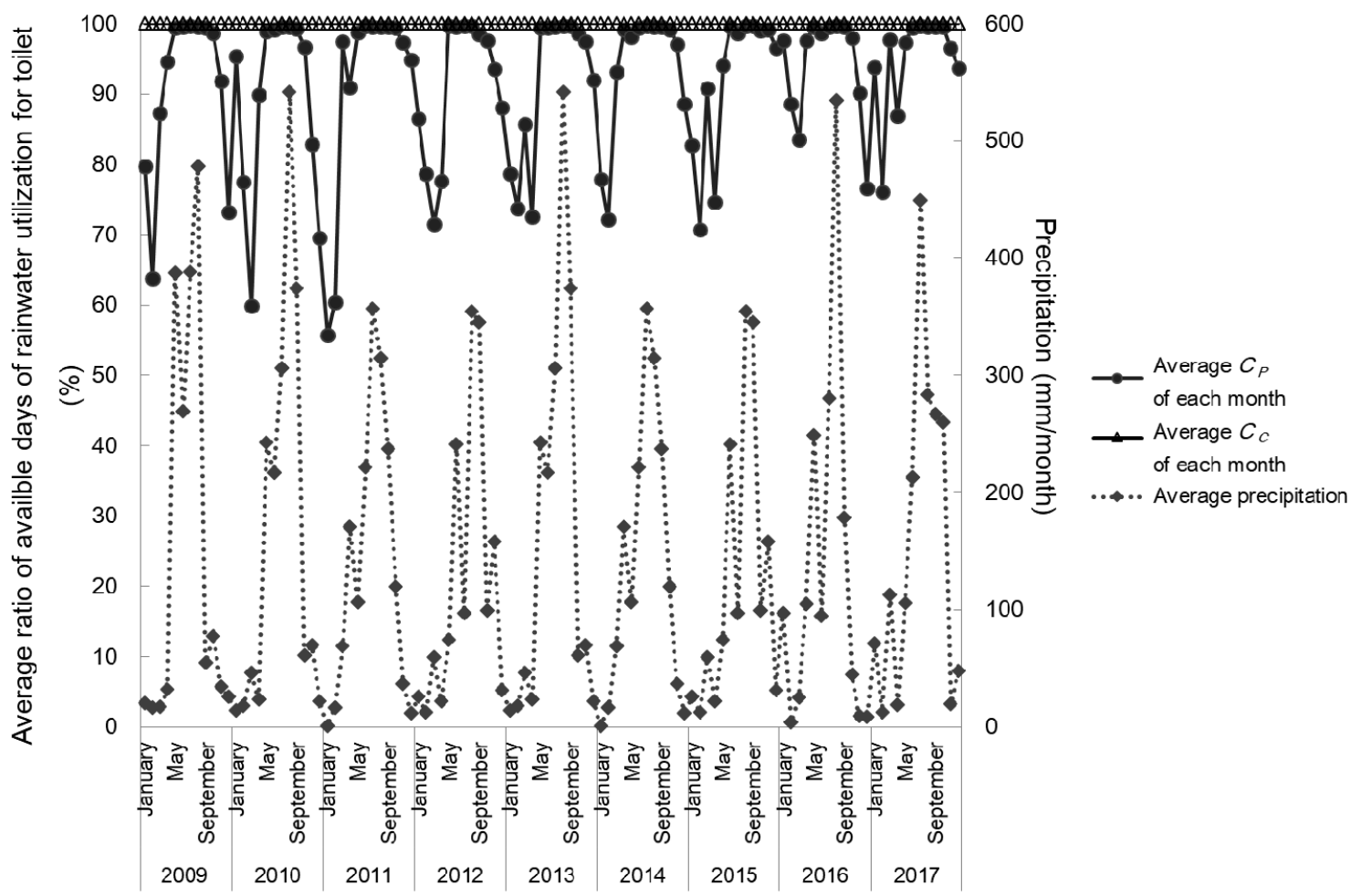

Figure 11. Seasonal change in covering ratio of supplied water with a tank of $7-\mathrm{m}^{3}$ at households having 3.6 persons.

\section{Discussion}

The probabilistic approach for estimating the rainwater utilization of households from the distributions of both the catchment area and the water demand exhibited that more than half of the households failed to achieve the potential that was estimated using the conventional approach. The conventional approach estimated the potential using the average roof area and the basis water demand. Such approach has been done in the majority of the previous studies, and the potential was treated to be homogeneous. However, the roof area should differ among households. In addition, not only the roof area, but also the water demand should depend on households. Even in the case of toilet-water demand, which is thought to be due to mainly appliance and not to human behavior, it differs among households as well as among countries or areas [39,40]. A study reported that people use various types of toilet such as single-flush toilets and dual-flush toilets in Hanoi. These toilets have different efficiency in water use. Even among dual-flush toilets, flush volume varies [40]. Thus, the roof 
area and the water demand should be uncertain variables, and the potential should be considered to be heterogeneous among water users. Some studies also emphasized that the probability distribution of water saving potential should be estimated based on the heterogeneousness of each parameter [40,41]. Hence, the probabilistic approach using the probability distributions of the roof areas and the water demands is expected to offer us a better understanding the efficiency of rainwater utilization in households as compared to that estimated by the conventional approach.

Additionally, the required tank size depended not only on the required covering ratio but also on the household size. Previous studies used the specific values of the water demand or roof area to estimate the appropriate tank size too [22,42], and it may considerably overestimate the potential and misunderstand the appropriate size. In contrast, the results of the probabilistic approach provided the necessary tank size that would satisfy the water demands of a specific proportion of households over a specific portion of the year and the proportion of households that were able to achieve a high covering potential using only a small tank. When the demands outstrip the standard water supply, these insights will assist the deployment of compensatory rainwater utilization. For example, when the supplied water can satisfy only $30 \%$ of a household's water demand, the probabilistic approach can assess the volume of the rainwater storage tank that satisfies the remaining $70 \%$ of the demand in the majority of the households. The probabilistic approach is also useful for ensuring that a specific ratio of households achieves a targeted covering ratio and for understanding the effect of household size on the potential of rainwater utilization.

As aforementioned, the demand fraction, the storage fraction, or the modified storage fraction have been used to discuss the uncertainty of the catchment area and the water demand in previous studies [24-27]. This methodology gives use as the information regarding the tank volume, which is suitable to install in a specific house having a specific demand fraction. By contrast, the probabilistic approach using the distributions of both the catchment area and the end-use water demand made it possible to consider the potential of rainwater utilization, based on the ratio of households, which can achieve a specific water demand. Hence, it was found that the proposed method is useful to get the detailed information on the difference of the potential of rainwater utilization among households in a given area.

Based on the estimated monthly potentials over a period of nine years, small precipitation was observed to reduce the potential of the rainwater utilization of the subsequent month. This indicates that the stored volume can be inadequate in the month after a low-rainfall month, even when precipitation of the month is high. However, in the case of our study area, the rainwater utilization remained efficient, even when the precipitation was small.

This approach can reveal the potential utilization of rainwater other than for usage in toilets, such as for outdoor and laundry purposes, which are considered to be suitable candidates for rainwater usage [20].

\section{Limitation}

This study has several limitations. The potential of rainwater utilization was discussed in households of different sizes: Average (3.6 persons/household), small (two persons/household), and large (five persons/household). However, if the probabilistic distribution of the household sizes is known, it can be incorporated into the simulation for a precise description of the potential rainwater-use distribution. Additionally, the probabilistic distribution of the catchment areas was obtained from the rooftop data in the peri-urban and rural areas of Hanoi. These areas are expected to adequately provide the probability distribution of the catchment areas in Hanoi, because urban areas generally contain few detached houses, and because the area of rainwater tank installation is adequate in the case of rural areas. However, if the probabilistic distribution of the catchment areas of the detached households were available throughout Hanoi, our simulations would yield more accurate results. In addition, the monthly data of precipitation was used for the simulations in this study for ten years, although previous research suggested that the time step resolution affect the results [26]. 
Removal of the first flush was not considered either, and removal of the first flush should reduce the possible volume of rainwater inflow into a tank. Yet, if the daily data of precipitation is available, we can assume the first flush removal for almost every rainfall, and it can give us more precise results.

\section{Conclusions}

We estimated the potential of rainwater utilization in households using a new simulation method that combined the randomly selected catchment-area and water-demand parameters. The probabilistic approach accounts for the differences in the catchment area and the water demand in different households. When compared with the results of the probabilistic approach, the conventional approach overestimated the usage potential. Additionally, the proposed method clarified the variable demands of differently-sized households to determine the size of rainwater tanks.

The proposed simulation method is useful to understand the manner in which the potential of rainwater utilization differs in a given area, and it can be applied to any area of which distributions of catchment-area and water-demand are available. It leads to an understanding of the demand volume of public water supply, which can be saved, and the best tank size to maximize the rainwater potential throughout the targeted area. In addition, conducting the proposed simulation for multi usage would indicate the optimal usage of rainwater in households (e.g., toilet, laundry, and outdoor), while taking the difference of water usage among households into account. These ideas are considered to be beneficial for evaluating the feasibility of water demand management using rainwater in households.

Author Contributions: Conceptualization, K.T., M.O. and Y.O.; Data curation, K.T. and M.O.; Formal analysis, K.T.; Funding acquisition, M.O. and Y.O.; Investigation, K.T.; Methodology, K.T. and M.O.; Project administration, Y.O.; Resources, M.O. and Y.O.; Supervision, M.O. and Y.O.; Validation, M.O. and Y.O.; Visualization, K.T.; Writing-original draft, K.T.; Writing—review \& editing, M.O. and Y.O.

Funding: This research was funded by JSPS: Japan Society for the Promotion of Science, Grant-in-Aid for Scientific Research (B), grant number JP17H01936 and JP18H04324.

Conflicts of Interest: The authors declare no conflict of interest.

\section{References}

1. Stavenhagen, M.; Buurman, J.; Tortajada, C. Saving water in cities: Assessing policies for residential water demand management in four cities in Europe. Cities 2018, 79, 187-195. [CrossRef]

2. Kummu, M.; Guillaume, J.H.A.; De Moel, H.; Eisner, S.; Flörke, M.; Porkka, M.; Siebert, S.; Veldkamp, T.I.E.; Ward, P.J. The world's road to water scarcity: Shortage and stress in the 20th century and pathways towards sustainability. Sci. Rep. 2016, 6, 1-16. [CrossRef] [PubMed]

3. OECD. OECD Environmental Outlook to 2050; OECD Publishing: Paris, France, 2012; Volume 2030, ISBN 9789264122246.

4. Xiong, W.; Li, Y.; Zhang, W.; Ye, Q.; Zhang, S.; Hou, X. Integrated multi-objective optimization framework for urban water supply systems under alternative climates and future policy. J. Clean. Prod. 2018, 195, 640-650. [CrossRef]

5. Charles, K.; Pond, K.; Pedley, S.; Hossain, R.; Guillarmod, F.J. Vision 2030: The Resilience of Water Supply and Sanitation in the Face of Climate Change, Technology Projection Study; University of Surrey: Guildford, UK, 2010; p. 81.

6. Fielding, K.S.; Spinks, A.; Russell, S.; McCrea, R.; Stewart, R.; Gardner, J. An experimental test of voluntary strategies to promote urban water demand management. J. Environ. Manag. 2012, 114, 1-9. [CrossRef] [PubMed]

7. Arbués, F.; García-Valiñas, M.Á.; Martínez-Espiñeira, R. Estimation of residential water demand: A state-ofthe-art review. J. Socio-Econ. 2003, 32, 81-102. [CrossRef]

8. Friedman, K.; Heaney, J.P.; Morales, M.; Palenchar, J. Water demand management optimization methodology. J. Am. Water Works Assoc. 2011, 103, 74-84. [CrossRef]

9. Beal, C.D.; Gurung, T.R.; Stewart, R.A. Demand-side management for supply-side efficiency: Modeling tailored strategies for reducing peak residential water demand. Sustain. Prod. Consum. 2016, 6, 1-11. [CrossRef] 
10. Baki, S.; Rozos, E.; Makropoulos, C. Designing water demand management schemes using a socio-technical modelling approach. Sci. Total Environ. 2018, 622-623, 1590-1602. [CrossRef] [PubMed]

11. Renwick, M.E.; Green, R.D. Do residential water demand side management policies measure up? An analysis of eight California water agencies. J. Environ. Econ. Manag. 2000, 40, 37-55. [CrossRef]

12. Imteaz, M.A.; Adeboye, O.B.; Rayburg, S.; Shanableh, A. Rainwater harvesting potential for southwest Nigeria using daily water balance model. Resour. Conserv. Recycl. 2012, 62, 51-55. [CrossRef]

13. Hurlimann, A. Household use of and satisfaction with alternative water sources in Victoria Australia. J. Environ. Manag. 2011, 92, 2691-2697. [CrossRef] [PubMed]

14. Dolnicar, S.; Hurlimann, A.; Nghiem, L.D. The effect of information on public acceptance-The case of water from alternative sources. J. Environ. Manag. 2010, 91, 1288-1293. [CrossRef] [PubMed]

15. National Research Council of the National Academies. Desalination: A National Perspective, Environmental Protection; The National Academies Press: Washington, DC, USA, 2008. [CrossRef]

16. Domenech, L. Rethinking water management: From centralised to decentralised water supply and sanitation models. Doc. Anàl. Geogr. 2011, 57, 293-310. [CrossRef]

17. UNEP. Rainwater Harvesting: A Lifeline for Human Well-Being; Stockholm Environment Institute: Stockholm, Sweden, 2009; Volume 41, p. 69. [CrossRef]

18. Australian Bureau of Statistics 4610.0-Water Account, Australia, 2013-14. Available online: http:/ / www.abs.gov.au/AUSSTATS/abs@.nsf/Previousproducts/4610.0MainFeatures32013-14?opendo cument\&tabname $=$ Summary\&prodno $=4610.0 \&$ issue $=2013-14 \&$ num $=\& v i e w=($ accessed on 11 June 2018).

19. Luong, T.V.; Luckmuang, P. Household rainwater harvesting-Thailand. In Proceedings of the 28th WEDC Conference, Sustainable Environmental Sanitation and Water Services, Kolkata, India, 18-22 November 2002; pp. 1-4.

20. Lee, K.E.; Mokhtar, M.; Hanafiah, M.M.; Halim, A.A.; Badusah, J. Rainwater harvesting as an alternative water resource in Malaysis: Potential, policies and development. J. Clean. Prod. 2016, 126, 218-222. [CrossRef]

21. Aladenola, O.O.; Adeboye, O.B. Assessing the potential for rainwater harvesting. Water Res. Manag. 2010, 24, 2129-2137. [CrossRef]

22. Ghisi, E.; Mengotti de Oliveira, S. Potential for potable water savings by combining the use of rainwater and greywater in houses in southern Brazil. Build. Environ. 2007, 42, 1731-1742. [CrossRef]

23. Silva, A.S.; Ghisi, E. Uncertainty analysis of daily potable water demand on the performance evaluation of rainwater harvesting systems in residential buildings. J. Environ. Manag. 2016, 180, 82-93. [CrossRef] [PubMed]

24. Fewkes, A. Modelling the performance of rainwater collection systems: Towards a generalised approach. Urban Water 1999, 1, 323-333. [CrossRef]

25. Liaw, C.H.; Chiang, Y.C. Dimensionless analysis for designing domestic rainwater harvesting systems at the regional level in Northern Taiwan. Water 2014, 6, 3913-3933. [CrossRef]

26. Campisano, A.; Modica, C. Selecting time scale resolution to evaluate water saving and retention potential of rainwater harvesting tanks. Procedia Eng. 2014, 70, 218-227. [CrossRef]

27. Campisano, A.; Modica, C. Regional scale analysis for the design of storage tanks for domestic rainwater harvesting systems. Water Sci. Technol. 2012, 66, 1-8. [CrossRef] [PubMed]

28. Otaki, Y.; Otaki, M.; Bao, P.N.; Nga, T.T.V.; Aramaki, T. Micro-component survey of residential water consumption in Hanoi. Water Sci. Technol. Water Supply 2013, 13, 469-478. [CrossRef]

29. Villarreal, E.L.; Dixon, A. Analysis of a rainwater collection system for domestic water supply in Ringdansen, Norrköping, Sweden. Build. Environ. 2005, 40, 1174-1184. [CrossRef]

30. General Statistics Office of Viet Nam Area, Population and Population Density by Province. Available online: http:/ / www.gso.gov.vn/default_en.aspx?tabid=774 (accessed on 15 October 2018).

31. Mitchell, V.G.; Mccarthy, D.T.; Deletic, A.; Fletcher, T.D. Urban stormwater harvesting-Sensitivity of a storage behaviour model. Environ. Model. Softw. 2008, 23, 782-793. [CrossRef]

32. Geraldi, M.S.; Ghisi, E. Influence of the length of rainfall time series on rainwater harvesting systems: A case study in Berlin. Res. Conserv. Recycl. 2017, 125, 169-180. [CrossRef]

33. General Statistics Office of Viet Nam Monthly Rainfall at Some Stations. Available online: http:/ / www.gso. gov.vn/default_en.aspx?tabid=773 (accessed on 11 June 2018).

34. Ndiritu, J.; Moodley, Y.; Guliwe, M. Generalized storage-yield-reliability relationships for analysing shopping centre rainwater harvesting systems. Water 2017, 9, 771. [CrossRef] 
35. Ward, S.; Memon, F.A.; Butler, D. Rainwater harvesting: Model-based design evaluation. Water Sci. Technol. 2010, 61, 85-96. [CrossRef] [PubMed]

36. Osaka Prefectural Government Daredemodekiru! Tanoshii Amamizu Riyou! (Everione Can Do It! Happy Utilisation of Rainwater!). Available online: http:/ /www.pref.osaka.lg.jp/attach/4725/00112927/jirei.pdf (accessed on 11 June 2018).

37. The International Benchmarking Network, The International Benchmarking Network for Water and Sanitation Utilities (IBNET). Available online: https:/ / www.ib-net.org/ (accessed on 19 October 2018).

38. General Statistics Office of Viet Nam, The 2009 Vietnam Population and Housing Census: Major Findings. Available online: https:/ / www.gso.gov.vn/default_en.aspx?tabid=515\&idmid=5\&ItemID=9813 (accessed on 11 June 2018).

39. Otaki, Y.; Otaki, M.; Pengchai, P.; Ohta, Y.; Aramaki, T. Micro-components survey of residential indoor water consumption in Chiang Mai. Drink. Water Eng. Sci. Discuss. 2008, 1, 45-70. [CrossRef]

40. Otaki, Y.; Otaki, M.; Aramaki, T. Potential of efficient toilets in Hanoi, Vietnam. Water Pract. Technol. 2018, 13, 621-628. [CrossRef]

41. Rosenberg, D.E. Probabilistic estimation of water conservation effectiveness. J. Water Res. Plan. Manag. 2007, 133, 39-49. [CrossRef]

42. Santos, C.; Taveira-Pinto, F. Analysis of different criteria to size rainwater storage tanks using detailed methods. Res. Conserv. Recycl. 2013, 71, 1-6. [CrossRef]

(C) 2018 by the authors. Licensee MDPI, Basel, Switzerland. This article is an open access article distributed under the terms and conditions of the Creative Commons Attribution (CC BY) license (http://creativecommons.org/licenses/by/4.0/). 